\title{
Commentary: The Circulatory Effects of Increased Hydrostatic Pressure Due to Immersion and Submersion
}

\author{
Jacques Regnard ${ }^{1 *}$, Malika Bouhaddi ${ }^{2}$, Olivier Castagna ${ }^{3,4}$ and Laurent Mourot ${ }^{5,6}$ \\ ${ }^{1}$ EA3920 Prognostic Factors and Regulatory Factors of Cardiac and Vascular Pathologies, University of Bourgogne \\ Franche-Comté, Besançon, France, ${ }^{2}$ Department of Physiology and Functional Testing, University Hospitals of Besançon, \\ EA3920 Prognostic Factors and Regulatory Factors of Cardiac and Vascular Pathologies, University of Bourgogne \\ Franche-Comté, Besançon, France, ${ }^{3}$ Underwater Research Team (ERRSO), Military Biomedical Research Institute (IRBA), \\ Toulon, France, ${ }^{4}$ UPR 66312 Human Motricity and Sport Health Expertise Laboratory (LAHMES), Azur Coast Nice University, \\ Nice, France, ${ }^{5}$ EA3920 Prognostic Factors and Regulatory Factors of Cardiac and Vascular Pathologies, Exercise \\ Performance Health Innovation (EPHI) Platform, University of Bourgogne Franche-Comté, Besançon, France, ${ }^{6}$ Division for \\ Physical Education, National Research Tomsk Polytechnic University, Tomsk Oblast, Russia
}

Keywords: immersion, gravity, hydrostatic pressure, Pascal's Law, blood reallocation, fluid movements

\section{OPEN ACCESS}

Edited by:

Costantino Balestra, Haute École Bruxelles-Brabant (HE2B), Belgium

Reviewed by:

Pierre Lafère,

Polyclinique du Trégor, France Miroslav Rozloznik,

University of Ostrava, Czechia

*Correspondence: Jacques Regnard jacques.regnard@univ-fcomte.fr

Specialty section:

This article was submitted to Environmental, Aviation and Space

Physiology,

a section of the journal

Frontiers in Physiology

Received: 07 December 2021 Accepted: 03 January 2022

Published: 27 January 2022

Citation:

Regnard J, Bouhaddi M, Castagna O and Mourot $L$ (2022) Commentary:

The Circulatory Effects of Increased Hydrostatic Pressure Due to Immersion and Submersion.

Front. Physiol. 13:830759. doi: 10.3389/fphys.2022.830759

\section{A Commentary on}

The Circulatory Effects of Increased Hydrostatic Pressure Due to Immersion and Submersion by Weenink, R. P., and Wingelaar, T. T. (2021). Front. Physiol. 12:699493. doi: 10.3389/fphys.2021.699493

We noted with interest the article by Weenink and Wingelaar published last July in Frontiers in Physiology (Weenink and Wingelaar, 2021). However, reading the abstract and the article was largely disappointing. We cannot agree with many statements made by the authors. In our opinion, their analysis of the physiological responses to immersion lacks precision in physical and physiological evidence presented, and cannot support the actual mechanisms underlying their findings.

One cannot assert with certainty that buoyancy reduces movement of fluid from the vascular to extracellular compartment. Also, the authors suggest that the hydrostatic force does not exert a compressive force on the body and this is not correct. In a fluid (liquid or gas), hydrostatic pressure acts in every direction on the sheath of the immersed object (or body). Buoyancy results from the upward force experienced by the whole object according to both the volume of fluid displaced and the difference between densities of the object/body and the fluid. For example, a hot air balloon gets buoyancy from the atmospheric (hydrostatic) pressure due to the lower density of the inner volume than the same atmospheric volume outside.

However, the "Archimedes principle" operating on the entire immersed human body does not exert any buoyancy effect inside the vascular network where gravity still acts on blood exactly as when outside water. In an upright position an immersed subjects' pulmonary tissue is still less distended in the base of the lungs which supports the whole lung weight than in the apex. XRay evidence of immersion pulmonary œedema appears in different lung areas that relates to the subject's position during the œdema development (Hårdstedt et al., 2020; Castagna et al., 2021). Similarly, degrees of lung ventilation and perfusion are known to change with subject's position in lying patients. Further, during immersion "Archimedes buoyancy" roughly equilibrates the weight of human body, but does not suppress gravitational effects. Thus, while the "weightlessness" sensed during immersion arises from this buoyancy, the immersed cardiovascular physiology remains different from cardiovascular physiology during real microgravity in orbit. Even though thoracic 
blood volume is increased under both conditions, in spacecrafts no external body compression operates nor does hydrostatic pressure (Regnard et al., 2001; Prisk, 2011). Relying simply on the word "weightlessness" is confusing in the context of a purposely comprehensive article.

Hydrostatic pressure is very much a compressing force able to squeeze compliant vessels and reduce total vascular capacity, which in an emerged state amounts to nearly five times the blood volume. Blood flow and volume are allocated to various parts of the vascular network according to circumstances: resting supine or upright, leg or arm exercising... Gradually increasing immersion exposure from the feet to the neck progressively reduces total vascular capacity (Koubenec et al., 1978). The compression by hydrostatic pressure and the accompanying displacement of blood volume immediately shifts this volume upon squeezing the leg and trunk vessels inducing enlarged heart chambers and an increased central venous pressure (Risch et al., 1978; Johansen et al., 1992, 1995, 1997). Likewise pneumatic anti-shock garments and g-suits compress and increase cardiac preload (Regnard et al., 1990; Gilbert et al., 1991). Similar reduction of vascular capacitance and displacement of blood volume are not produced when people are placed in dry hyperbaric chambers. Three bars in compressed air does not compress leg and thigh vessels nor increase heart dimension by even one tenth of a bar in water. Upright water immersion up to heart level creates a hydrostatic pressure around the ankle of e.g., $125 \mathrm{~cm} \mathrm{H}_{2} \mathrm{O}$ or $90 \mathrm{mmHg}$, which roughly equals hydrostatic pressure in the body blood column (at the ankle level). In air the ankle skin is subjected to an external atmospheric pressure of $0.11 \mathrm{mmHg}$ higher that at the heart level (800 times lower than the internal hydrostatic pressure), and in compressed air at a 3-bar pressure, the external atmospheric pressure at the ankle is only $0.34 \mathrm{mmHg}$ higher than at heart level. Hydrostatic pressure applied to the skin is transmitted by tissues of grossly hydric density (hence little compressible as skin, muscles, liver, kidney...) at the adventitial side of vessels to exert a squeezing effect. Because room is available in other parts of the vascular network (pelvic, mesenteric, lung...), blood is shifted in more or less incompletely filled vessels. This shift of blood volume operates no matter the position, i.e., independently of gravity direction relative to the body. Quite similar pulmonary and heart engorgement occurs in upright and supine immersed subjects, as reflected in the autonomic nervous system adjustments in heart rate and vasomotor tone (Bahjaoui-Bouhaddi et al., 2000; Mourot et al., 2007, 2008). A cold-triggered vasoconstriction can be added without or with face cooling (Mourot et al., 2008).

The external hydrostatic pressure changes the transmural pressure in vessel walls, which in capillaries and venules affect microvascular filtration between the vascular and interstitial spaces. In governing these exchanges gravity controls blood pressure (hydrostatic pressure) differently from interstitial pressure (e.g., with postural changes), leading to microvascular filtration or conversely plasma reabsorption (Hagan et al., 1978).
The time constant of transmural fluid exchange is much higher than that of blood displacement across vascular beds. Thus, upon immersion the rapid (about $1 \mathrm{~s}$ time constant) increase in thoracic blood volume results from arrival of blood from the compressed legs and thigh muscles and then from the abdominal vessels (Risch et al., 1978; Regnard et al., 1990; Johansen et al., 1997). The much slower increase in plasma volume (hemodilution) is due to reabsorption of interstitial and intracellular fluids, largely in the lower limbs (Greenleaf et al., 1980; Johansen et al., 1992, 1997; Pendergast et al., 2015). The "Perspective" article by Weeninck and Wingelaar missed the pivotal distinction between rapid blood translocation between vascular beds (Risch et al., 1978; Gilbert et al., 1991), and the much slower (and long lasting) interstitial fluid reabsorption from extravascular space that leads to the increased urine output (Johansen et al., 1992, 1997; Castagna et al., 2013).

After firstly dismissing any hydrostatic compression effect and suggesting buoyancy is at play, the authors then rely on the compressive effect of "tight fitting suits" to make their arguments. It is of note that the pressure exerted by elastic neoprene suit has been accurately measured (Castagna et al., 2013) and yes hydrostatic pressure acts as elastic stocking (Tipton et al., 2017) and can reduce microvascular filtration or induce interstitial fluid reabsorption (Johansen et al., 1997).

The analysis of immersed lung mechanics improperly refers to Pascal's Law, which operates on incompressible fluids, not on lung gas spaces. The miscellaneous discussion (section "Additional factors to consider") is inaccurate regarding the data presently available (Wilmshurst et al., 1989; Castagna et al., 2018; Wilmshurst, 2019). It is not true that after immersed cooling a subject is in a vasoplegic state. In fact the reduction in large cold-induced arterial and venous vasoconstrictive tone occurs over several hours (Robinet et al., 2006; Boussuges et al., 2009; Florian et al., 2013; Riera et al., 2014). Yes removing the squeezing effect of hydrostatic pressure precipitate rescue collapse (Lloyd, 1992).

As presented in the paper several physical or physiological concepts are misleadingly described and some related statements are therefore uninformative and difficult to accept. Quoted as they were, these perspectives had to be cautiously considered. Much recent factual evidence is not considered. Main physiological effects of immersion are sometimes too simply explained adding confusion and bordering on misleading. All this can putatively detract from a clear understanding for the readers.

\section{AUTHOR CONTRIBUTIONS}

JR wrote the first draft. MB, OC, and LM added contributions and revised the manuscript. The final version was approved by all authors. 


\section{REFERENCES}

Bahjaoui-Bouhaddi, M., Cappelle, S., Henriet, M. T., Dumoulin, G., Wolf, J. P., and Regnard, J. (2000). Graded vascular autonomic control versus discontinuous cardiac control during gradual upright tilt. J. Auton. Nerv. Syst. 79, 149-155. doi: 10.1016/S0165-1838(99)00068-5

Boussuges, A., Gole, Y., Mourot, L., Jammes, Y., Melin, B., Regnard, J., et al. (2009). Haemodynamic changes after prolonged water immersion. J. Sports Sci. 27, 641-649. doi: 10.1080/02640410902717001

Castagna, O., Blatteau, J.-E., Vallee, N., Schmid, B., and Regnard, J. (2013). The underestimated compression effect of neoprene wetsuit on divers hydromineral homeostasis. Int. J. Sports Med. 34, 1043-1050. doi: 10.1055/s-0033-1345136

Castagna, O., Michoud, G., Prevautel, T., Delafargue, A., Schmid, B., Similowski, T., et al. (2021). Broad individual immersion-scattering of respiratory compliance likely substantiates dissimilar breathing mechanics. Sci. Rep. 11, 9434. doi: 10.1038/s41598-021-88925-x

Castagna, O., Regnard, J., Gempp, E., Louge, P., Brocq, F. X., Schmid, B., et al. (2018). The key roles of negative pressure breathing and exercise in the development of interstitial pulmonary edema in professional male SCUBA divers. Sports Med. Open 4:1. doi: 10.1186/s40798-017-0116-x

Florian, J. P., Simmons, E. E., Chon, K. H., Faes, L., and Shykoff, B. E. (2013). Cardiovascular and autonomic responses to physiological stressors before and after six hours of water immersion. J. Appl. Physiol. 115, 1275-1289. doi: 10.1152/japplphysiol.00466.2013

Gilbert, I. A., Regnard, J., Lenner, K. A., Nelson, J. A., McFadden, E. R. Jr. (1991). Intrathoracic airstream temperatures during acute expansions of thoracic blood volume. Clin Sci. 81, 655-661. doi: 10.1042/cs0810655

Greenleaf, J. E., Shvartz, E., Kravik, S., and Keil, I. C. (1980). Fluid shifts and endocrine responses during chair rest and water immersion in man. J. Appl. Physiol. 48, 79-88. doi: 10.1152/jappl.1980.48.1.79

Hårdstedt, M., Seiler, C., Kristiansson, L., Lundeqvist, D., Klingberg, C., and Braman Eriksson, A. (2020). Swimming-induced pulmonary edema: diagnostic criteria validated by lung ultrasound. Chest 158, 1586-1595. doi: 10.1016/j.chest.2020.04.028

Hagan, R. D., Diaz, F. J., and Horvath, S. M. (1978). Plasma volume changes with movement to supine and standing positions. J. Appl. Physiol. 45, 414-417. doi: 10.1152/jappl.1978.45.3.414

Johansen, L. B., Bie, P., Warberg, J., Christensen, N. J., and Norsk, P. (1995). Role of hemodilution on renal responses to water immersion in humans. Am. J. Physiol. 269, R1068-76. doi: 10.1152/ajpregu.1995.269.5.R1068

Johansen, L. B., Foldager, N., Stadeager, C., Kristensen, M. S., Bie, P., Warberg, J., et al. (1992). Plasma volume, fluid shifts, and renal responses in humans during $12 \mathrm{~h}$ of head-out water immersion. J. Appl. Physiol. Bethesda Md 1985 73, 539-544. doi: 10.1152/jappl.1992.73.2.539

Johansen, L. B., Jensen, T. U. S., Pump, B., and Norsk, P. (1997). Contribution of abdomen and legs to central blood volume expansion in humans during immersion. J. Appl. Physiol. 83, 695-699. doi: 10.1152/jappl.1997.83.3.695

Koubenec, H. J., Risch, W. D., and Gauer, O. H. (1978). Effective compliance of the circulation in the upright sitting posture. Pflugers Arch. 374, 121-124. doi: 10.1007/BF00581291

Lloyd, E. L. (1992). The cause of death after rescue. Int. J. Sports Med. 13(Suppl. 1), S196-199. doi: 10.1055/s-2007-1024638

Mourot, L., Bouhaddi, M., Gandelin, E., Cappelle, S., Dumoulin, G., Wolf, J.-P., et al. (2008). Cardiovascular autonomic control during short-term thermoneutral and cool head-out immersion. Aviat. Space Environ. Med. 79, 14-20. doi: 10.3357/ASEM.2147.2008
Mourot, L., Bouhaddi, M., Gandelin, E., Cappelle, S., Nguyen, N. U., Wolf, J.-P., et al. (2007). Conditions of autonomic reciprocal interplay versus autonomic co-activation: effects on non-linear heart rate dynamics. Auton. Neurosci. 137, 27-36. doi: 10.1016/j.autneu.2007.0 6.284

Pendergast, D. R., Moon, R. E., Krasney, J. J., Held, H. E., and Zamparo, P. (2015). Human physiology in an aquatic environment. Compr Physiol. 5, 1705-1750. doi: 10.1002/cphy.c140018

Prisk, G. K. (2011). Pulmonary circulation in extreme environments. Compr. Physiol. 1, 319-338. doi: 10.1002/cphy.c090006

Regnard, J., Beji, M., Zidani, R., Combalot, M., Lockart, A., and Dall'Ava, J. (1990). Increase in thoracic blood volume on inflation of antishock trousers estimated by inductive plethysmography. Eur. Respir. J. 3:127s.

Regnard, J., Heer, M., Drummer, C., and Norsk, P. (2001). Validity of microgravity simulation models on Earth. Am. J. Kidney Dis. 38, 668-674. doi: 10.1053/ajkd.2001.27753

Riera, F., Horr, R., Xu, X., Melin, B., Regnard, J., and Bourdon, L. (2014). Thermal and metabolic responses of military divers during a 6-hour static dive in cold water. Aviat. Space Environ. Med. 85, 509-517. doi: 10.3357/asem.30 77.2014

Risch, W. D., Koubenec, H. J., Gauer, O. H., and Lange, S. (1978). Time course of cardiac distension with rapid immersion in a thermo-neutral bath. Pflugers Arch. 374, 119-120. doi: 10.1007/BF00581290

Robinet, C., Galland, F.-M., Hugon, M., Boussuges, A., Desruelle, A.-V., Jammes, Y., et al. (2006). Experiment on "Long duration immertsion" in cold water. Eur. J. Underw. Hyperb. Med. 7, 75-78.

Tipton, M. J., Collier, N., Massey, H., Corbett, J., and Harper, M. (2017). Cold water immersion: kill or cure? Exp. Physiol. 102, 1335-1355. doi: 10.1113/EP086283

Weenink, R. P., and Wingelaar, T. T. (2021). The circulatory effects of increased hydrostatic pressure due to immersion and submersion. Front. Physiol. 12:699493. doi: 10.3389/fphys.2021.699493

Wilmshurst, P. T. (2019). Immersion pulmonary oedema: a cardiological perspective. Diving Hyperb. Med. 49, 30-40. doi: 10.28920/dhm49.1.30-40

Wilmshurst, P. T., Nuri, M., Crowther, A., and Webb-Peploe, M. M. (1989). Cold-induced pulmonary oedema in scuba divers and swimmers and subsequent development of hypertension. Lancet Lond. Engl. 1, 62-65. doi: $10.1016 /$ S0140-6736(89)91426-8

Conflict of Interest: The authors declare that the research was conducted in the absence of any commercial or financial relationships that could be construed as a potential conflict of interest.

Publisher's Note: All claims expressed in this article are solely those of the authors and do not necessarily represent those of their affiliated organizations, or those of the publisher, the editors and the reviewers. Any product that may be evaluated in this article, or claim that may be made by its manufacturer, is not guaranteed or endorsed by the publisher.

Copyright (0 2022 Regnard, Bouhaddi, Castagna and Mourot. This is an open-access article distributed under the terms of the Creative Commons Attribution License (CC $B Y)$. The use, distribution or reproduction in other forums is permitted, provided the original author(s) and the copyright owner(s) are credited and that the original publication in this journal is cited, in accordance with accepted academic practice. No use, distribution or reproduction is permitted which does not comply with these terms. 